\title{
Analysis of Thermo-Mechanical Behaviour of Air Compressor in Automotive Braking System
}

\author{
J. Venkatesan, S. P. Chidambaram, G. Nagarajan, Anand Suresh, and K. Saravanan
}

\begin{abstract}
The modern automotive vehicles with air brake system and air assisted hydraulic brake system use reciprocating air compressor with disc, reed or ring valves. Automotive compressors are run by engine itself. Well designed compressor will consume less power and deliver maximum flow of air thereby reducing the power taken from the I.C. engine. This indirectly reduces the fuel consumption of engine and thereby pollution. The mathematical model will be an effective tool in compressor design and for analysing the thermo-mechanical behaviour of compressor in working condition. This paper aims at analysing the thermo-mechanical behaviour of the air compressor used in automotive braking system using compressor model developed with the help of fundamental equations and experimental results. Experiment results are obtained from a 160 cc air cooled compressor with $80 \mathrm{~mm}$ bore and $32 \mathrm{~mm}$ stroke to validate the developed model performance. The effect of operating parameters, like, discharge pressure, compressor speed, etc., on thermodynamic and mechanical behaviour of compressor such as cylinder pressure, cylinder volume, cylinder temperature, valve lift and resultant torque at different crank angles and free air delivered and indicated power of the compressor was analysed.
\end{abstract}

Index Terms - Volumetric efficiency, free air delivered, reed valve, peak pressure, valve lift.

\section{INTRODUCTION}

From the early days of Henry Ford's first automobile to the hybrids and sports cars of today, vehicle technology has come a long way. For several decades, automotive safety didn't keep pace with the exponential growth of the auto industry, but with today's safety measures, the rate of fatal traffic accidents is on the decline. One of the predominant reasons for accident is brake failure. A poorly designed or an improperly maintained braking system causes a brake failure resulting in major accidents. A well designed braking system prevents accidents due to brake failure. Reciprocating compressors are used in commercial automotives with air brake system. They are in use for more than six decades.

\section{A. Air Compressor in Braking System}

Air brakes or air assisted hydraulic brakes use

Manuscript received March 18, 2017; revised June 15, 2017.

J. Venkatesan, S. P. Chidambaram, Anand Suresh, and K. Saravanan are with the Department of Automobile Engineering, Sri Venkateswara College of Engineering, Pennalur, Chennai, India (e-mail: jvenkat@scve.ac.in, chidhu95@gmail.com, anandsuresh25@gmail.com, saravanakrish96@gmail.com).

G. Nagarajan. is with the Department of Mechanical Engineering, Anna University, Chennai, India. compressed air to make the brakes work. The compressor is the main part of the brake system. It pumps the air into the air storage tanks. The reciprocating air compressor is connected to the engine through gears or a V-belt. The compressor may be air-cooled or may be cooled by the engine cooling system. When the air tank pressure rises to the "cut-out" level, the governor stops the compressor from pumping the air. When the tank pressure falls to the "cut-in" level the governor allows the compressor to start pumping again. Since an automotive air compressor is run by engine itself, it consumes a significant amount of high grade mechanical energy of the engine that comes from the combustion of fuel.

\section{B. Compressor Model}

The engineers at the design stage will try to analyze the outcome of their work related to performance and life at various operating and physical conditions. Mathematical model is an effective tool to predict the performance of a compressor at any working condition. The designer will be in a position to know the outcome at the initial stage of the proposed work and thereby reducing the time and cost of experimental work.

\section{Important Factors Considered in Modeling [1], [2]}

1. In actual compressors, the suction or discharge valve plays a vital role. The air enters the cylinder through filter and head that results in a pressure drop in the flow path. Therefore, the mass corresponding to the volume displaced by the piston will not be equal to the mass entering the cylinder through the suction port or flow area [3]. The wall temperature will not be equal to the atmospheric temperature as in the case of ideal compressors. The movement of the piston with piston rings generates heat and it is dissipated to the air and cylinder wall. This heat addition to the air raises the suction temperature and affects the pressure pattern during suction. Therefore, the available thermodynamic equations cannot be used directly to determine the various properties of air during operation.

2. During discharge process, there will be a pressure rise. There may be intermediate opening and closing of valves during discharge. And this will create a pressure pulsation during the discharge process.

3. The volumetric efficiency of the compressor cannot be calculated based on the pressure ratio and clearance ratio, since constant pressure ratio in the cycle is not attained. Therefore the volumetric efficiency should be calculated from the actual mass delivered per cycle.

\section{Compressor Valves}

The performance of the compressor greatly depends on the valve behavior [4] which varies with operating speed 
and pressure. A compressor valve is a device that controls the inward flow of lower pressure gas at atmospheric conditions and the outward flow of higher pressure gas from a reciprocating compressor cylinder. Normally these valves open and close automatically, solely governed by the pressure differential in the cylinder and the intake or exhaust line pressure. There is atleast one suction valve and one discharge valve for every compression chamber as shown in Fig. 1. Each valve opens and closes in every cycle. A valve used in a compressor operating at $1200 \mathrm{rpm}$ for 12 hours a day and 280 days a year, opens and closes 72,000 times per hour or 864,000 times per 12 hours in a day or 241,920,000 times per year. There are different kinds of compressor valves: plate or disc valves [3], [5], ring valves, channel valves, feather valves, poppet valves, ball valves, reed and concentric valves, to name just a few. Each design has specific criteria [6], [7] with regard to the sealing element and all the other components are designed accordingly. Most of the air compressors used in automotive braking system use reed, disc or ring valves.
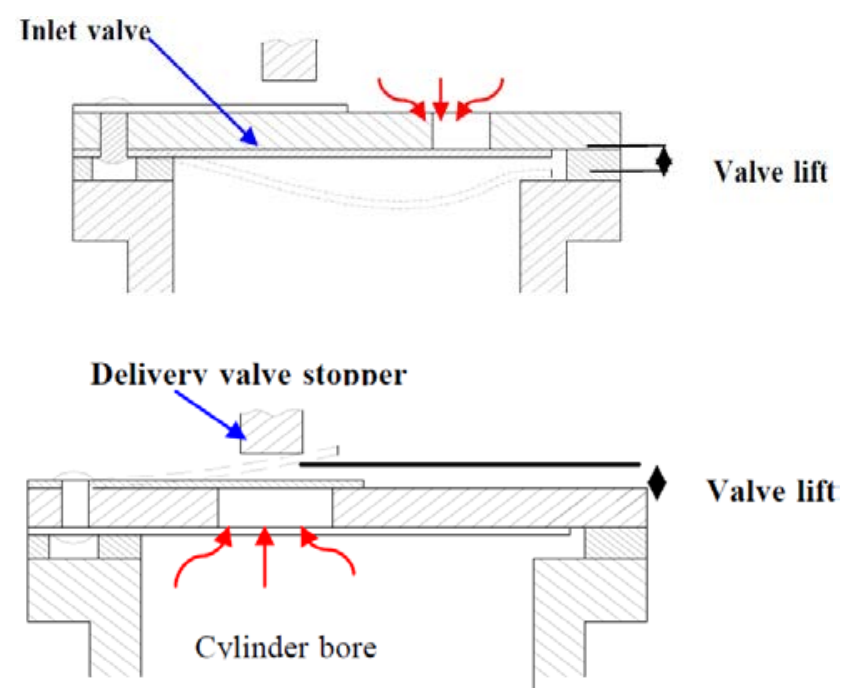

Fig. 1. Inlet and delivery reed valve openings.

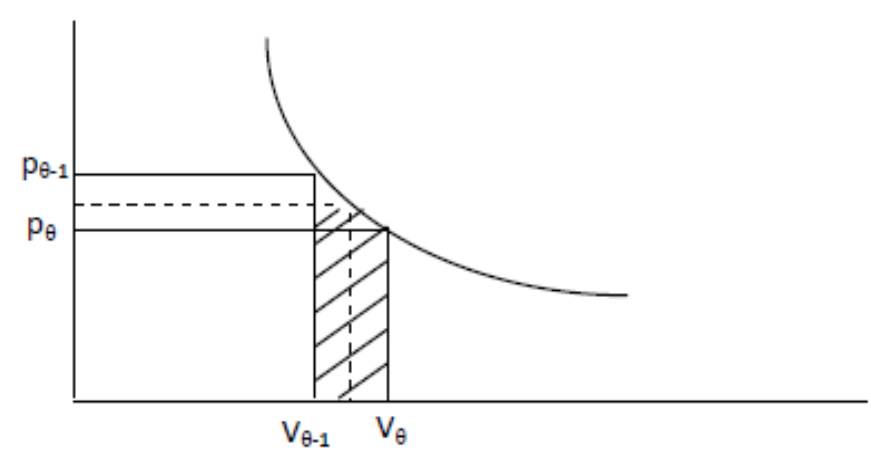

Fig. 2. Integration method of determining IP.

\section{FUndAMENTAL EQUATIONS FOR COMPRESSOR MODELING}

Suction:

$$
\left[m C_{v} \frac{d T}{d t}+\frac{m R T}{V} \frac{d V}{d t}+\frac{d m_{s}}{d t}\left(C_{v} T-R T_{s}\right)-\frac{d Q}{d t}\right] \frac{\Delta \theta}{\omega}=0
$$

Compression and Re-expansion:

$$
\left[m C_{v} \frac{d T}{d t}+\frac{m R T}{V} \frac{d V}{d t}-\frac{d Q}{d t}\right] \frac{\Delta \theta}{\omega}=0
$$

Discharge:

$$
\left[m C_{v} \frac{d T}{d t}+\frac{m R T}{V} \frac{d V}{d t}+\frac{d m_{d}}{d t}\left(R T_{d}-C_{v} T\right)-\frac{d Q}{d t}\right] \frac{\Delta \theta}{\omega}=0
$$

Governing equation for determining the instantaneous cylinder pressure is

$$
\frac{p v}{R T}=1+\sum_{i=1}^{n} B_{i}(T) \rho_{i}
$$

The second term in equation (2.4) accounts for compressibility factor and is negligible for single stage reciprocating air compressors [1], [2].

Governing equation for determining the mass flow is

$$
\frac{d m}{d \theta}=\frac{d m_{i}}{d \theta}-\frac{d m_{o}}{d \theta}-\sum \frac{d m_{o p}}{d \theta}
$$

where, $m_{o p}$ is mass of air flowing through the gap between the piston and the cylinder wall.

\section{A. Indicated Power (IP)}

The area under the curve in a $p$ - $V$ diagram is work transfer or indicated power transfer. Fig. 2. shows the integration method of determining the indicated power of the actual compressor cycle.

Since all the processes do not follow the particular thermodynamic law, standard equations cannot be used for estimating the IP.

The general and effective model used for estimating IP during any incremental crankangle is

$$
I P_{\theta}=I P_{\theta-1}+\left(V_{\theta-1}-V_{\theta}\right)\left(\frac{p_{\theta-1}+p_{\theta}}{2}\right)\left(\frac{N}{60}\right)
$$

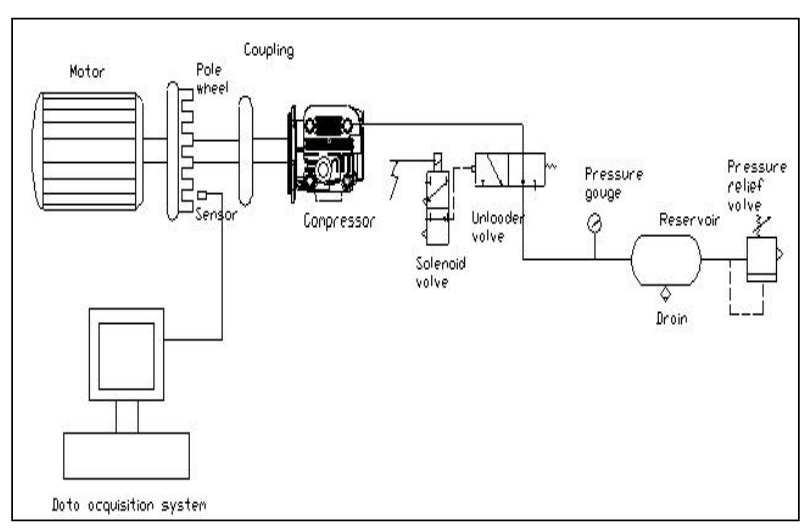

Fig. 3. Experimental set up.

\section{EXPERIMENTAL SETUP}

The compressor used in braking system of heavy passenger vehicles and trucks was tested using sophisticated test rig as shown in Fig. 3. The compressor was run by an electric motor. The pressure inside the cylinder is captured by the AVL Piezo-electric pressure transducer and the data was stored using Data acquisition system. The compressor speed was controlled by a speed regulator in the control panel. The compressor was cooled by a fan.

The specification of compressor under test is shown in 
Table I.

\begin{tabular}{|l|c|}
\hline TABLE I: SPECIFICATION OF COMPRESSOR \\
\hline Crank radius [mm] & 80 \\
\hline Length of connecting rod [mm] & 16 \\
\hline Clearance volume [cc] & 85.4 \\
\hline Suction valve type & 5 \\
\hline Delivery valve type & Reed \\
\hline Mass of suction valve [g] & Reed \\
\hline Mass of delivery valve [g] & 10.8 \\
\hline Number of suction ports & 4.3 \\
\hline Number of delivery ports & 4 \\
\hline Cooling & 2 \\
\hline
\end{tabular}

\section{ANALYSIS AND DiSCUSSIONS}

The simulated results are shown in Table II.

TABLE II: Comparison of SimUlated Results (Discharge PRESSURE

\begin{tabular}{|c|c|c|c|}
\hline & Ideal & $\begin{array}{c}\text { Predicte } \\
\text { d }\end{array}$ & $\begin{array}{c}\text { Experimen } \\
\text { tal }\end{array}$ \\
\hline$p_{\max }[\mathrm{bar}]$ & 9 & 12.31 & 12.01 \\
\hline FAD [lpm] & 425.5 & 269.9 & 279.1 \\
\hline $\mathrm{VE}[\%]$ & 88.2 & 55.9 & 58.1 \\
\hline IP [W] & 2167 & 2332 & 2350 \\
\hline
\end{tabular}

The variation of cylinder air pressure with crankangle and cylinder volume is shown in Fig. 4 and Fig. 5 respectively. It can be observed from the compression and expansion curves predicted by the model that the curves match closely with experimental curves. The pressure variation during suction and discharge at different crankangles predicted by the model is comparable with the Cheema (1993) has reported that the resistance offered to flow by the cylinder casting can be equal to the resistance offered by the valves. Constricted flow areas adjacent to a valve contribute a significant amount of pressure loss because they impose changes in velocity and direction. This delays the start of suction or discharge in a cycle. From Fig. 4 and 5, it is observed that the compression starts at $318^{\circ}$ crankangle and the corresponding pressure is 12.31 bar which is the maximum pressure in the cycle. It is concluded that the discharge will start at a pressure which is greater than the discharge pressure. This delay is due to the initial compression of valve and flow resistances as mentioned by Cheema. But, in ideal compressor the discharge is assumed to start at discharge pressure [8], [9]. Similar phenomenon takes place during the suction process. The pressure will always be less than the intake air pressure.

Fig. 6 shows the predicted variation of cylinder air temperature. The temperature of air during the suction is found to be greater than the atmospheric temperature. The higher suction air temperature is due to the heating of incoming air by hot cylinder head and cylinder wall [10]. Also the temperature is not constant during the suction process as in the ideal compression cycle. The temperature of air during suction process gradually decreases because of expansion of air due to the movement of the piston with high velocity.

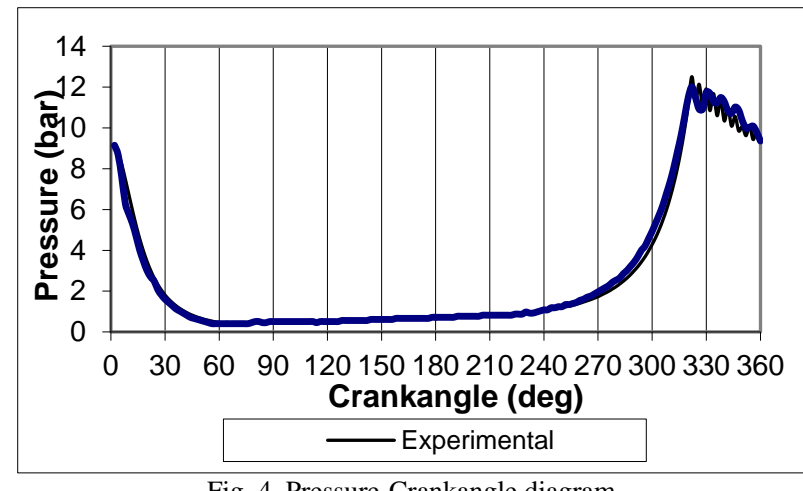

Fig. 4. Pressure-Crankangle diagram

(Discharge Pressure = 9 bar (abs), Speed = 3000 rpm)

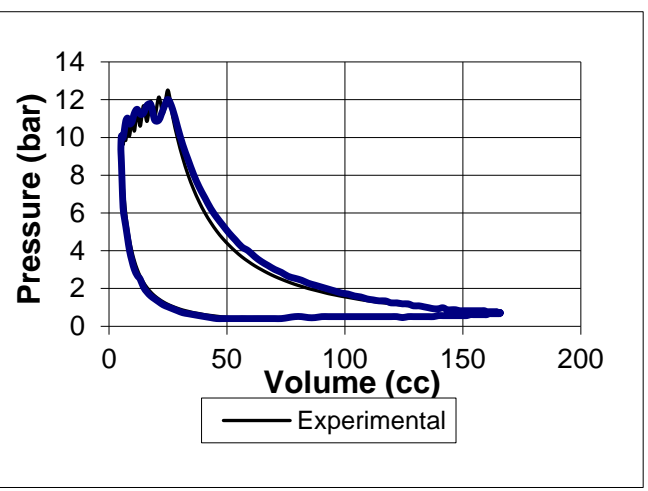

Fig. 5. Pressure-Volume diagram

(Discharge Pressure = 9 bar (abs), Speed = 3000 rpm)

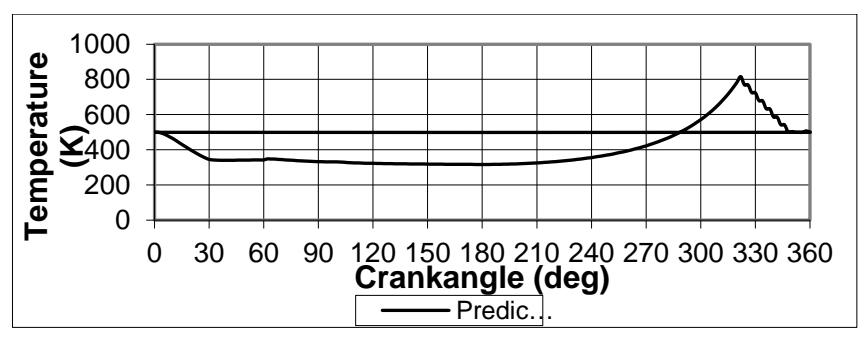

Fig. 6. Temperature-Crankangle diagram

(Discharge Pressure $=9$ bar $(\mathrm{abs})$, Speed $=3000 \mathrm{rpm}$ ).

During compression the temperature increases until the start of discharge process as the air is compressed in a non flow process. The temperature of air decreases during the discharge process as there is no compression of air during this period. Temperature fluctuations are predicted during the discharge process because of the many intermediate compression and expansion of air with the intermediate closing and opening of discharge valve.

The valve lift or displacement at different crankangles during suction and discharge is shown in Fig. 7. Davis.H (1990) in his work on compressor valves reported that the pressure fluctuations during suction or discharge are the direct indication of valve fluttering. The pattern is comparable with the experimental values of cylinder air pressure during suction and discharge periods. It can be also be observed from Fig.7 that the suction starts at around 
$62^{\circ}$ crankangle while discharge starts at $318^{\circ}$ crankangle. There is a slight vibration of suction valve compared to discharge valve which vibrates rapidly. During suction the valve experiences less force due to little pressure difference while the pressure difference during discharge is more which causes the discharge valve to experience higher forces. Complete closing and opening of valves are pronounced both in suction and discharge processes. It can also be observed that the discharge valve does not close immediately at the beginning of re-expansion of air in the clearance volume. This is because, the discharge is continuing a few degrees after TDC till the pressure difference between the delivery head and the cylinder reaches zero.

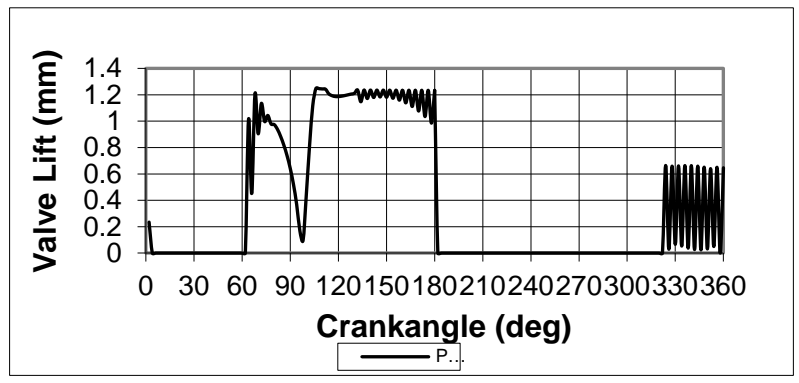

Fig. 7. Valve lift-Crankangle diagram

(Discharge Pressure $=9$ bar (abs), Speed = $3000 \mathrm{rpm})$.

Fig. 8 shows the variation of compressor torque with crankangle. The resultant torque may be negative or zero or positive depending on the dominance of inertia and pressure forces. The acceleration of the piston which is dependent on crank radius, connecting rod length and crankangle, may be negative or zero or positive. The net force on the piston is a function of instantaneous cylinder pressure and acceleration at a particular crankangle. At lower crankangles $\left(<90^{\circ}\right)$ and higher crankangles $\left(>270^{\circ}\right)$ the acceleration of the piston is positive, while at other crankangles the acceleration is negative.

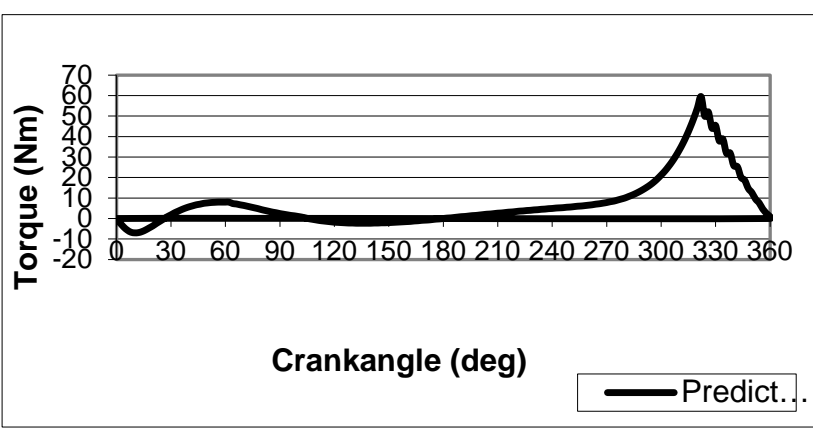

Fig. 8. Resultant torque-Crankangle diagram (Discharge Pressure = 9 bar (abs), Speed = $3000 \mathrm{rpm}$ ).

Fig. 9 shows the variation of piston velocity, acceleration and torque with crankangles. During suction the cylinder pressure is always less than or equal to crankcase pressure. Therefore the pressure force (the first term in Equation (2.4)) is negative or zero during suction. The inertia force (the second term in Equation (2.4)) is dominant at lower crankangles. Inertia force is dominant from $0^{\circ}$ to $27^{\circ}$ and $116^{\circ}$ to $180^{\circ}$ and hence the torque is negative during these periods. At all other crankangles the pressure force is dominating and this makes the torque positive. The maximum torque is experienced at the end of compression. The position of the crank at which the torque is zero is dependent on the cylinder pressure and the crank and connecting rod lengths.

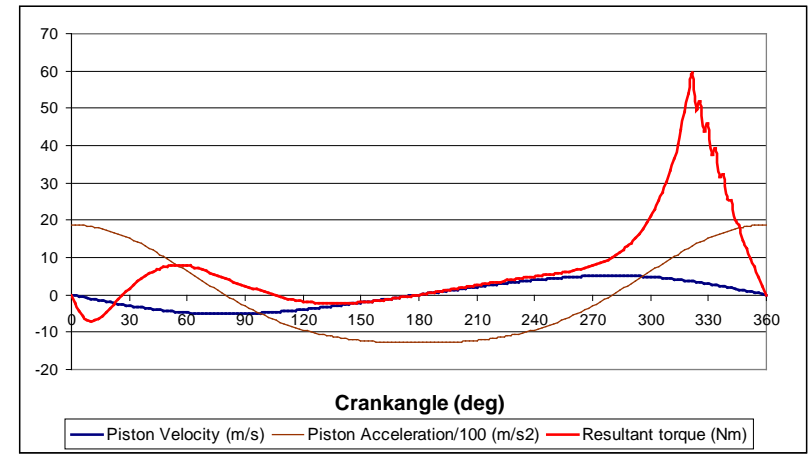

Fig. 9. Velocity, acceleration and torque diagram.

Fig. 10 shows the volumetric efficiency at different speeds. In ideal compressor cycle the volumetric efficiency decreases with speed. But, in actual cycle the volumetric efficiency first increases and then decreases.

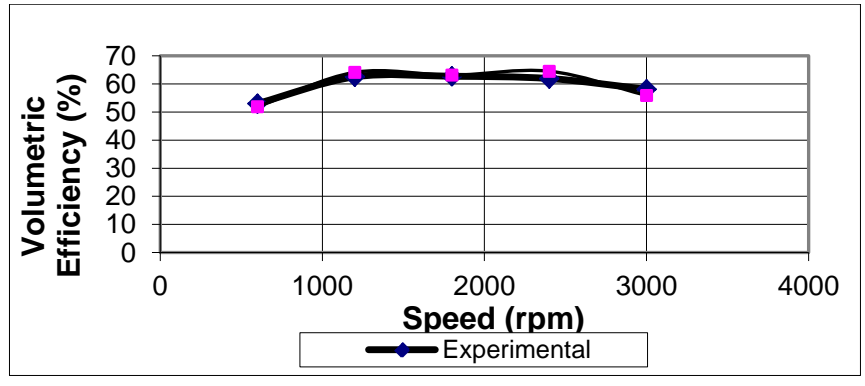

Fig. 10. Variation of volumetric efficiency with speed (Discharge Pressure $=9$ bar (abs)) .

At lower speeds there is an increase in volumetric efficiency because of the increased time available for more air to enter the cylinder during suction process. The volumetric efficiency deteriorates as the speed increases. At higher speeds, the vacuum created by the suction is more and valve flutters more. This effect reduces the volumetric efficiency at higher speeds.

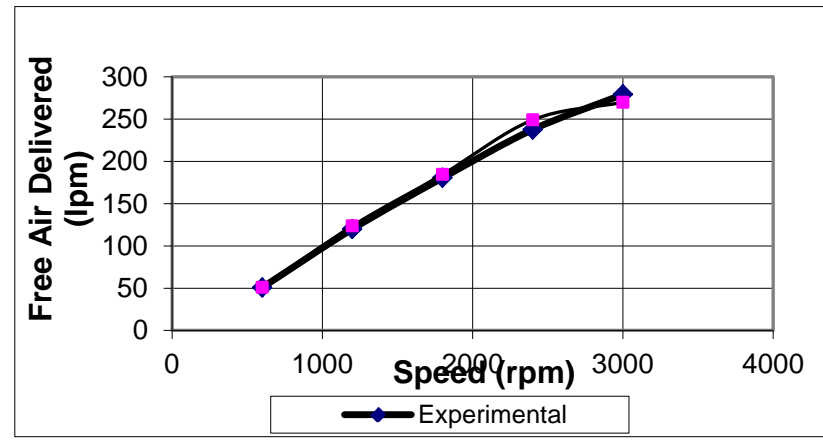

Fig. 11. Variation of FAD with speed (Discharge Pressure $=9$ bar (abs)).

Fig. 11 shows the effect of compressor speed on FAD. The FAD increases with speed, but the rate of increase in FAD decreases marginally with speed as the suction of air is affected at higher speeds as mentioned in the previous paragraph.

The indicated power at various compressor speeds is 
shown in Fig. 12. From the literatures and research works it

is concluded that the indicated power of the cycle increases with speed and discharge pressure.

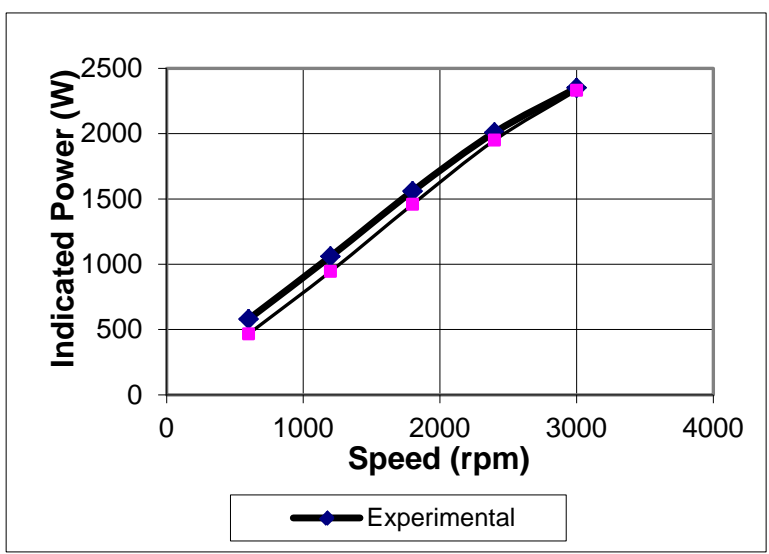

Fig. 12. Variation of indicated power with speed (Discharge Pressure $=9$ bar (abs)).

\section{CONCLUSIONS}

Developed model predicts fluctuation of pressure during suction and discharge processes. Model also predicts valve fluttering during suction and delivery processes at all delivery pressures and speeds.

4. The simulated results from the model are comparable with the experimental results. The accuracy of results from model is mainly dependent on the proper selection of various constants like, coefficient of discharge, area correction factors, etc. The temperature with which the air enters the cylinder is a function of speed. It increases with speed and it has to be selected properly to obtain reasonable FAD and volumetric efficiency.

5. It is possible to get Volumetric efficiency, Free air delivered, Indicated power, Cylinder air pressure, Cylinder air temperature, Resultant torque and Mass of air drawn in or discharged out per cycle, by varying any operating parameters like, speed, discharge pressure, etc., and physical parameters like, clearance volume, crank radius, connecting rod length and cylinder diameter.

6 . In general the model can predict the values with an average deviation of $\pm 6 \%$ at any discharge pressure and compressor speed.

\section{NOMENCLATURE}

$\begin{array}{ll}T & : \\ \theta & : \\ p & : \\ V & : \\ P_{\max } & : \\ \rho & : \\ m & : \\ Q & :\end{array}$

Temperature
Crank angle
Pressure
Volume
Peak Pressure
Density of air
Instantaneous mass
Heat transfer to actuating medium

$\begin{array}{lll}F A D & : & \text { Free Air Delivered } \\ V E & : & \text { Volumetric Efficiency } \\ I P & : & \text { Indicated Power }\end{array}$

\section{Subscripts}

$\begin{array}{lll}s & : & \text { Suction } \\ d & : & \text { Delivery } \\ e & : & \text { Effective }\end{array}$

\section{REFERENCES}

[1] J. Venkatesan, G. Nagarajan, R. V. Seeniraj, and S. Sampath, "Mathematical model for theoretical investigation of a disc valve reciprocating air compressor of automotive braking system," International Journal of Applied Mathematical Analysis and Applications, vol. 2, no. 1-2, pp. 209-227, 2007.

[2] J. Venkatesan, G. Nagarajan, R. V. Seeniraj, and R. Murugan, "Experimental validation of a mathematical model of a reed-valve air compressor from an automotive braking system," International Journal of Automotive Technology, vol. 11, no. 3, pp. 317-322, 2010.

[3] S. H. Joergensen, Danfoss, and Nordborg, "Transient valve plate vibrations" in Proc. of International Conference on Compressor Technology, Purdue University, West Lafayette, Indiana, USA, 1980.

[4] A. M. Bredesen, "Computer simulation of valve dynamics as an aid to design,” Norwegian Institute of Technology-in Proc. International Conference on Compressor.

[5] W. Soedel and R. W. Herrick, "Design and mechanics of compressor valves," in Proc.1980 Conference on Laboratories, School of Mechanical Engineering, Purdue University, West Lafayette, Indiana, USA, 1984.

[6] Cheema, S. Gurmeet, and McDonald, "Measurement of internal cylinder equivalent flow areas and effect of piston masking of valves," in Proc. 8th International Reciprocating Machinery Conference, Technical Paper, no. 2, Denver, Colorado, Sept. 1993, pp. 20-23.

[7] K. Suefuji and S. Nakayama, "Practical method for analysis and estimation of reciprocating hermetic compressor performance," Proceedings of International Conference on Compressor Technology, Purdue University, West Lafayette, Indiana, USA, 1980.

[8] H. Davis, "Industrial reciprocating and rotary compressor design and operation problems,” in Proc. I.ECH.E. Conference, London Paper, 1990, no. 2, pp. 9-23.

[9] S. Lawson. and R. J. L. McLaren., “An approach to computer modeling of reciprocating compressors," Proceedings of the 1984 Purdue Compressor Technology Conference, Purdue University, West Lafayette, Indiana, USA, 1984.

[10] C. Tian., Y. Liao and X. Li, "A Mathematical model of variable displacement swash plate compressor for automotive air conditioning system," International Journal of Refrigeration, Technology, Purdue University, West Lafayette, Indiana, USA, 1974, vol. 29, issue 2, pp. 270-280, 2005.

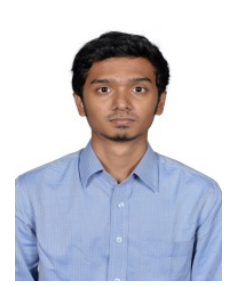

Chidambaram Subramanian was born on September 15, 1995 in Chennai, India. Chidambaram is pursuing bachelor of engineering (automobile engineering) degree at Anna University, Chennai, Tamil Nadu, India. Chidambaram has also attended a summer school at RWTH Aachen University, Germany, automotive and mobility in 2015.

His first Industry exposure was in 2014 Internship at India pistons, piston rings department. Later in 2015, he had worked in the Research and Development department of Albonair as an Intern. He was also the author for 'Simulation of a motorcycle motion during braking at cornering using MATLAB'(Chennai, Tamil Nadu: Applied mechanics and materials journal listed in annexure -2 Journals, Anna University). His research interest includes, vehicle dynamics, emission reduction and hybrid powertrains.

Mr. Chidambaram Subramanian is a part of the society of automotive engineers. 